\title{
Los espacios del cine en Jaén (1898-1966)
}

\author{
Luis Rueda Galán \\ Universidad de Jaén \\ Ifrg0001@red.ujaen.es
}

RESUMEN: El presente trabajo, a través del análisis histórico y artístico de las fuentes de archivo, de hemeroteca y gráficas disponibles, estudia los distintos espacios arquitectónicos que ocupó el cine en la ciudad de Jaén, desde la primera proyección datada en 1898 hasta el estreno, en 1966, del último edificio que se construye dedicado exclusivamente a esta función, en las siguientes páginas se ofrece una panorámica de la evolución de la tipología de la sala de cine en la ciudad. El estudio se divide en dos partes, la primera dedicada a los espacios utilizados antes de la aparición de la tipología de la sala de cine, mientras que la segunda lo hace de los construidos una vez que esta se ha instalado en el repertorio de soluciones de los arquitectos españoles.

PALABRAS CLAVE: Salas de Cine, Arquitectura, Jaén, Siglo XX.

\section{Cinema Sites in Jaén}

ABSTRACT: This paper presents the results of the study of the different buildings devoted to Cinema in the city of Jaén, by analysing documentary and visual sources. From the very first screening, in 1898 in a large booth, until the opening, in 1966, of the last great building constructed exclusively for this function, we offer an overview of the movie theater typology evolution in the city. This study is divided into two parts, the first one deals with the spaces used before the emergence of the movie theater proper; while the second one does the same with the buildings designed after the typology had been assumed as a valid solution by Spanish architects.

KEYWORDS: Cinema Theaters, Architecture, Jaén, $20^{\text {th }}$ Century.

Recibido: 18 de enero de 2016 / Aceptado: 22 de junio de 2016.

\section{El cine antes de los cines. Los primeros espacios de proyección}

Como es sabido, el tipo arquitectónico de la sala de cine comienza a gestarse en los primeros años del siglo XX a partir fundamentalmente de la tipología teatral, cristalizando posteriormente en una propia ya en la década de 1920. En nuestro país, como en el resto de Europa, antes de que quedaran fijadas sus características definitorias, el catálogo de espacios utilizados para las proyecciones fue variado.

\subsection{Los barracones cinematográficos}

De una parte proliferaron en todo el territorio nacional los empresarios que, de forma ambulante, llevaron el cinematógrafo de ciudad en ciudad. Normalmente, y de forma especial en los primeros años de desarrollo del medio, hasta aproximadamente 1910, lo hacian recorriendo las principales ferias y celebraciones populares, en las cuales levantaban sus barracas aprovechando la asistencia masiva de público. En Andalucía, por ejemplo, contamos con un caso paradigmático de este modelo

RUEDA GALÁN, Luis: «Los espacios del cine en Jaén (1898-1966)», Boletín de Arte, n. ${ }^{\circ}$ 37, Departamento de Historia del Arte, Universidad de Málaga, 2016, pp. 189-202, ISSN: 0211-8483. 
de explotación comercial del cinematógrafo en su primera etapa de vida en la figura del empresario granadino Antonio de la Rosa (Barrientos, 2003). De su animada actividad por el centro y sur del país ${ }^{1}$ se tiene constancia desde 1897, tan solo unos meses después de la primera proyección ofrecida en España, hasta al menos 1910, cuando instala su pabellón en Cádiz durante la feria de Navidad tras haber pasado una temporada en Jaén².

Pese a que no queda constancia documental del nombre del promotor del evento, todo apunta a que fue Antonio de la Rosa el empresario que organizó la primera serie de proyecciones registrada en la capital giennense, celebrada durante los primeros días de mayo de $1898^{3}$. La ocasión elegida no respondía a ninguna fiesta popular, sino a una función patriótica para recaudar fondos con destino a la guerra que se acababa de iniciar contra los EE. UU. Una práctica habitual, por otra parte, de Antonio de la Rosa esta de celebrar funciones benéficas a favor de instituciones de las distintas ciudades por las que pasaba. El Cinematógrafo de la Rosa volvería a Jaén, esta vez sí con motivo de la feria de octubre, prácticamente todos los años desde 1898 hasta al menos 1910, instalando su barracón bien en la propia plaza de San Francisco, centro neurálgico de la ciudad antigua, o en la mucho más amplia del Mercado ${ }^{4}$, espacio preferencial del ocio de los giennenses al menos desde la Baja Edad Media hasta bien avanzado el siglo $X X^{5}$. No fue el cinematógrafo de Antonio de la Rosa el único que visitó Jaén durante los primeros años del siglo XX. En octubre de 1903 queda documentada en el Ayuntamiento la solicitud que realiza Baldomero Ayuso para instalar su pabellón de proyecciones cinematográficas en la plaza de San Francisco, con total seguridad para ofrecer funciones durante la feria de aquel año ${ }^{6}$. En cuanto a las características y aspecto del barracón de Antonio de la Rosa no se han podido localizar de momento demasiados datos. Pero no es nada aventurado asumir que compartía las de otras barracas cinematográficas de principios de siglo: simplicidad constructiva, a base de estructuras de madera (Pérez Rojas, 1986: 69), generando un espacio sencillo y fácil de transportar, dedicado por completo a las localidades.

En muchas ciudades españolas algunos de estos barracones se hicieron estables y evolucionaron hacia pabellones con estructuras más complejas y fachadas más elaboradas, aún en gran parte de madera, pero ya con un tratamiento arquitectónico, como si de un edificio más se tratase (Pérez Rojas, 1986: 69). Las fachadas resultan sin duda lo más interesante. Su diseño respondía a la necesidad de actuar como reclamos para atraer el público, por el cual el cine competía directamente en sus inicios con otros espectáculos de atracción. De ahí que se encontraran frecuentemente decoradas con profusión, de forma mayoritaria en el lenguaje del modernismo arquitectónico en su versión más decorativa (Pérez Rojas, 1986: 69). Este hecho se explica, de una parte, porque ambos fenómenos, cine y modernismo, coinciden temporalmente, pero porque además ambos compartían una misma percepción de novedad y modernidad que favoreció su frecuente asociación (Sánchez, 2013: 265), influyendo de forma directa en la arquitectura de los primeros cinematógrafos estables muy pocos años después. De este modo los pabellones cinematográficos se convierten en un factor muy a tener en cuenta en la difusión de este estilo arquitectónico en España ${ }^{7}$, en especial en las ciudades de provincias alejadas de los grandes focos de actividad creativa, generalmente más refractarias a la introducción de una arquitectura considerada exótica por muchos sectores, resultando curiosamente, una vez más en la historia de la arquitectura, el campo de lo efímero un adecuado banco de pruebas de nuevos estilos.

Progresivamente fueron dando paso a los primeros cines, algunos de ellos resultado de la sustitución directa de pabellones cinematográficos por edificios de obra. Aunque en la provincia de Jaén existe algún interesantísimo ejemplo de cine primitivo ${ }^{8}$, en la capital no se registra la presencia de ninguno de ellos en la primera década del siglo, entre otras cuestiones porque la demanda se encontraba ampliamente satisfecha con los cinematógrafos instalados en teatros, salones y los barracones que acudían a las ferias.

\subsection{Salones de variedades}

La otra opción mayoritaria, también presente desde el mismo inicio de la exhibición cinematográfica en el país, consistía en la proyección en locales estables dedicados a otras actividades (salones de variedades, cafés, etc.), ya fuese mediante un cinematógrafo ambulante o bien establecido de forma permanente en el local. No se debe olvidar que, sin ir más lejos, la primera proyección española se organiza el día 
1. El Teatro Cervantes muy poco tiempo después de su estreno en 1907 (Instituto de Estudios Giennenses)

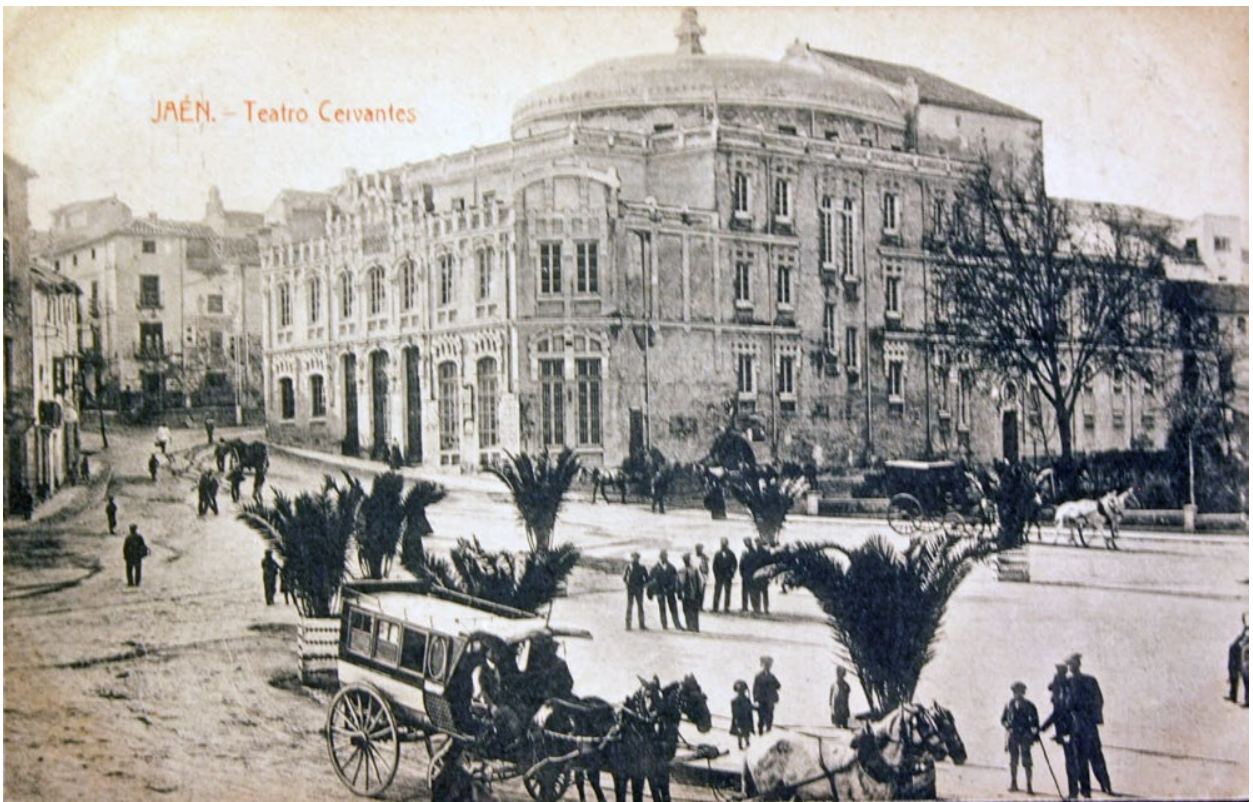

13 de mayo de 1896 en un salón, el del antiguo Hotel Rusia de la madrileña Carrera de San Jerónimo (Cánovas, 1993: 107). Los salones gozaban de la ventaja de poder explotar económicamente el cinematógrafo más allá de la temporada con climatología favorable, en la que se agrupaban la mayoría de las distintas fiestas locales, cuestión que la condición efímera de los pabellones no facilitaba.

Pese a que el ambiente de los salones de variedades era, las más de las veces, decididamente popular, el cine pasaba ahora a ocupar un espacio con algo más de entidad cultural que el de los barracones de feria. En Jaén las proyecciones en salones se registran casi de forma paralela a la aparición de los barracones ambulantes. En ellos, al igual que las barracas instaladas en las ferias, debían competir con las distintas atracciones. El cinematógrafo aquí compartía el protagonismo en los programas con los diferentes espectáculos que componían las conocidas como variedades (cantantes de cuplés, bailarinas, espectáculos teatrales, pero también ilusionistas, humoristas o funambulistas, entre muchos otros). Dos salones incluían el cinematógrafo en su oferta durante los primeros años del siglo XX en Jaén. El primero de ellos era el Salón Apolo, situado en las inmediaciones de la calle Campanas y propiedad del empresario Hilario Furió, del que sabemos que programó sesiones al menos desde el mes de enero de $1906^{\circ}$ y durante casi todo el año. El segundo, era el Salón Iris, situado en la actual calle Martínez Molina, y del que también encontramos las primeras noticias sobre proyecciones a partir del mismo $1906^{10}$. Normalmente los salones no poseían en propiedad el aparato proyector, que de una forma itinerante similar a lo ocurrido con los barracones de feria, llegaba a la ciudad y se instalaba en un salón durante un periodo de tiempo, finalizado el cual se trasladaba a otro" ${ }^{11}$. Que los dos salones de variedades más importantes de la ciudad ofrecieran simultáneamente sesiones de cinematógrafo es otro índice claro de la rápida popularidad que adquiere dentro de las preferencias de ocio de sus habitantes.

\subsection{El cine entra en el teatro}

Al mismo tiempo se produce la inclusión del cinematógrafo en los programas de los teatros. Para el cine va a suponer un paso capital para su afianzamiento como una de las actividades de ocio preferidas de los giennenses. Entre otras cuestiones, pasaba a formar parte de uno de los espacios tradicionales de la cultura, que de este modo sancionaba el propio carácter cultural del espectáculo cinematográfico, el 
cual, como acabamos de ver, había formado parte hasta el momento de la oferta de establecimientos mucho más populares. Esta entrada ilustra, en definitiva, tanto el aumento de consideración cultural del cine, así como de su creciente éxito de público, al disponer los teatros de un aforo mucho mayor que los salones de variedades.

El primer teatro giennense que va a celebrar sesiones cinematográficas va a ser el recién estrenado Teatro Cervantes en la plaza del Deán [1]. La ciudad de Jaén, con una importante afición al teatro y con espacios escénicos estables al menos desde el siglo XVII (Coronas, 1983: 1545-1558), se encuentra a principios del siglo XX con la necesidad de un teatro de referencia, al haber quedado sin uso en los últimos años del anterior el Principal, un edificio construido a partir de 1830 en la plaza de la Audiencia siguiendo los parámetros habituales de los teatros decimonónicos (Ulierte, 1990: 146). En 1904 se constituye a tal efecto una «Sociedad Anónima Constructora de un Teatro" con un capital social de 150.000 pesetas (Hurley, 1996: 351), convocándose concurso público para su diseño al año siguiente ${ }^{12}$.

El proyecto ganador ${ }^{13}$, obra de un recién titulado arquitecto malagueño, Manuel Rivera Vera (1879-1940), quien en su ciudad natal llevaría a cabo posteriormente una destacada trayectoria como diseñador de cines y teatros (cines Goya ,1923 y Plus Ultra, 1927, o Teatro Echegaray, 1932) (Lara García, 1999), se materializa finalmente en 1907, fecha de su apertura al público. Su moderno lenguaje ecléctico con evidentes influjos secesionistas y, sobre todo, su carga decorativa van a suponer una novedad en la ciudad, puesto que la tradición constructiva de la capital había establecido una arquitectura menos ornamentada y con un carácter más funcional. Las primeras noticias de funciones de cinematógrafo en el Cervantes datan del año 1908, en cuyo invierno se instala uno que está en funcionamiento hasta enero del año siguiente ${ }^{14}$. El Cervantes, que nunca perdió su condición de teatro, se convertiría no obstante con el tiempo en uno de los cines de referencia de Jaén hasta su cierre en 1968, siendo lamentablemente demolido en 1972.

El otro teatro giennense en el que el cinematógrafo hace acto de presencia desde el mismo momento de su estreno es El Norte. Situado en el entonces Paseo de Alfonso XIII, hoy de la Estación, en su actual número 13, ocupó el mismo solar en el que décadas después se levantaría el Cine Asuán. Se trata de un teatro con una historia algo compleja y que sufrió varias remodelaciones a lo largo de su existencia. Nace como salón de espectáculos anexo a la Cervecería El Norte, inaugurada en el mes de julio de 1910, contando ya desde ese momento con un cinematógrafo dentro de su oferta $^{15}$. Como testimonio del edificio primitivo desgraciadamente nos quedan solo algunas fotografías, por lo que, más allá del aspecto de su fachada, poco más podemos conocer con certeza. Esta ofrecía, no obstante, gran interés, ya que se trata de uno de los escasos ejemplos de edificios de estética Art Nouveau de la ciudad. Debemos acercar su autoría sin demasiadas dudas a la obra del arquitecto municipal del momento, Antonio Merlo y García de Pruneda, activo en Jaén entre los años 1904 y 1918, el único, por otra parte, del que hay constancia documental de que empleara el lenguaje modernista en la capital. Las razones que empujan a atribuir el diseño a Merlo, ante la ausencia de documentación al respecto, son de naturaleza estilística. Esta primitiva fachada de El Norte compartía muchas similitudes a nivel decorativo con otras obras del propio Merlo en Jaén ${ }^{16}$. Como veíamos en el caso del Cervantes, las funciones de cinematógrafo en El Norte, programadas durante estos años iniciales de su actividad, se limitan a solo dos noches a la semana ${ }^{17}$, alternándose con otros espectáculos como el baile o el teatro.

El Norte sufre una gran transformación a partir de octubre de 1917 cuando, ya documentada la propiedad del doctor Federico del Castillo Extremera, un destacado personaje de la vida social y política de la ciudad durante la primera mitad de siglo, se proyecta una remodelación que lo convierte en teatro de verano. El responsable del diseño fue el arquitecto burgalés, afincado en Madrid, Manuel Mendoza y Sáez de Argandoña ${ }^{18}$ [2], quien en sus primeros años de carrera profesional en la capital del país destacó como uno de los jóvenes arquitectos que mejor interpretó las variantes secesionista y Liberty del modernismo (Rocha, 2009: 314315). Su nueva fachada, con paramentos de mampostería vista, consistía en un cuerpo central, con los accesos bajo un gran arco con doble vano en la planta baja ${ }^{19}$ y una galería con columnas en el primero, entre dos torres, fue diseñada en un lenguaje decorativo característico del tardoeclecticismo en el que resuenan ecos procedentes de la arquitectura vienesa de fines del XIX, en la línea, por ejemplo, de las primeras obras madrileñas de Antonio Palacios. El teatro, tras la remodelación de Mendoza, se estrena el 24 de julio de 1918, contando desde entonces con una temporada esta- 
2. Fachada del Teatro El Norte en el proyecto de reforma de Manuel Mendoza (1919) (AMJ)

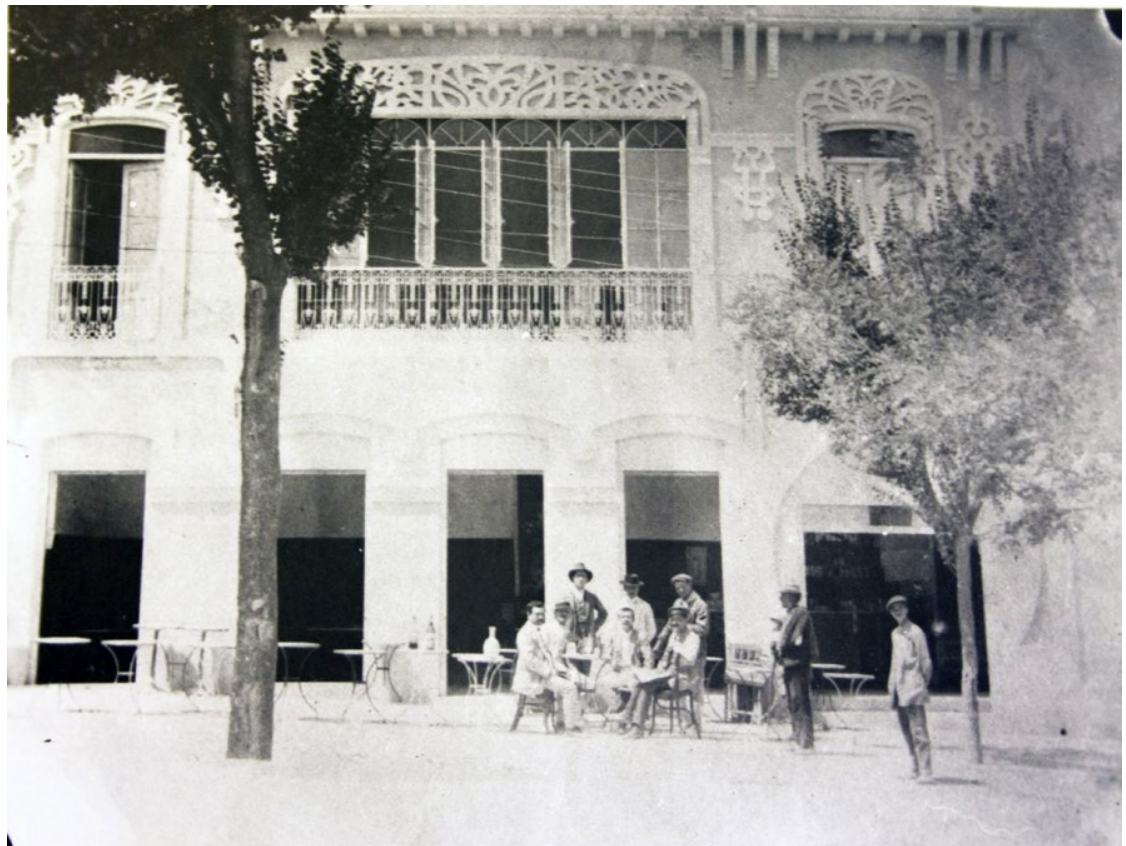

ble de cine de verano hasta el cese de su actividad a finales de la década de 1950, aunque alternando con funciones de teatro, espectáculos musicales e incluso, en la convulsa década de 1930, con mítines políticos. Tras una década de abandono es demolido y sustituido en 1966 por el, también desaparecido, Cine Asuán.

\section{Salas de nueva planta}

\subsection{Los primeros cines. Eclecticismo y regionalismo}

El primer espacio dedicado expresamente al espectáculo cinematográfico en Jaén con un carácter estable fue el Cine Darymelia. Si bien se levantó aprovechando algunas partes del ya citado Teatro Principal, los cambios que sufrió, tanto en su aspecto externo como estructuralmente, fueron tan importantes que hay que considerarlo como un edificio de nueva planta. A fines del año 1902, el arquitecto provincial y diocesano, propietario además del inmueble, Justino Flórez Llamas (1850-1927) presenta unos planos en el Ayuntamiento con objeto de remodelarlo ${ }^{20}$. Pero el proyecto no saldría adelante, entre otras cuestiones, quizá influido por la competencia que supuso el inicio de las gestiones para la construcción del Cervantes tan solo un par de años después ${ }^{21}$. Finalmente en 1923, en una fecha en la que el cinematógrafo ya se ha asentado en los gustos del público giennense e instalado desde hacía más de una década en otros teatros de la ciudad, Flórez, prepara un nuevo proyecto de reforma, en esta ocasión reconvertido en cine ${ }^{22}$, abriendo sus puertas al público en 1927.

El arquitecto vacía completamente el interior del edificio, eliminando la planta de herradura del antiguo teatro y diseñando una sala más diáfana y rectangular, característica ya de los primeros cines. No obstante conservó la caja del escenario para la celebración de funciones teatrales, lo que hace que podamos encajarlo dentro del tipo de los cines-teatro tan frecuentes aún en las décadas de 1920-30. Sustituye por otro lado la cubierta original del teatro por una estructura metálica, un recurso poco habitual en la arquitectura giennense de la época pese a su amplia difusión desde el último tercio del XIX, si exceptuamos el notable ejemplo que supuso la que diseñó Manuel Rivera para cubrir el Cervantes. Resulta más interesante analizar su fachada [3]. Justino Flórez Llamas, quien contaba 73 años cuando firmó el proyecto del Darymelia, fue un arquitecto con una sólida formación historicista ${ }^{23}$. 


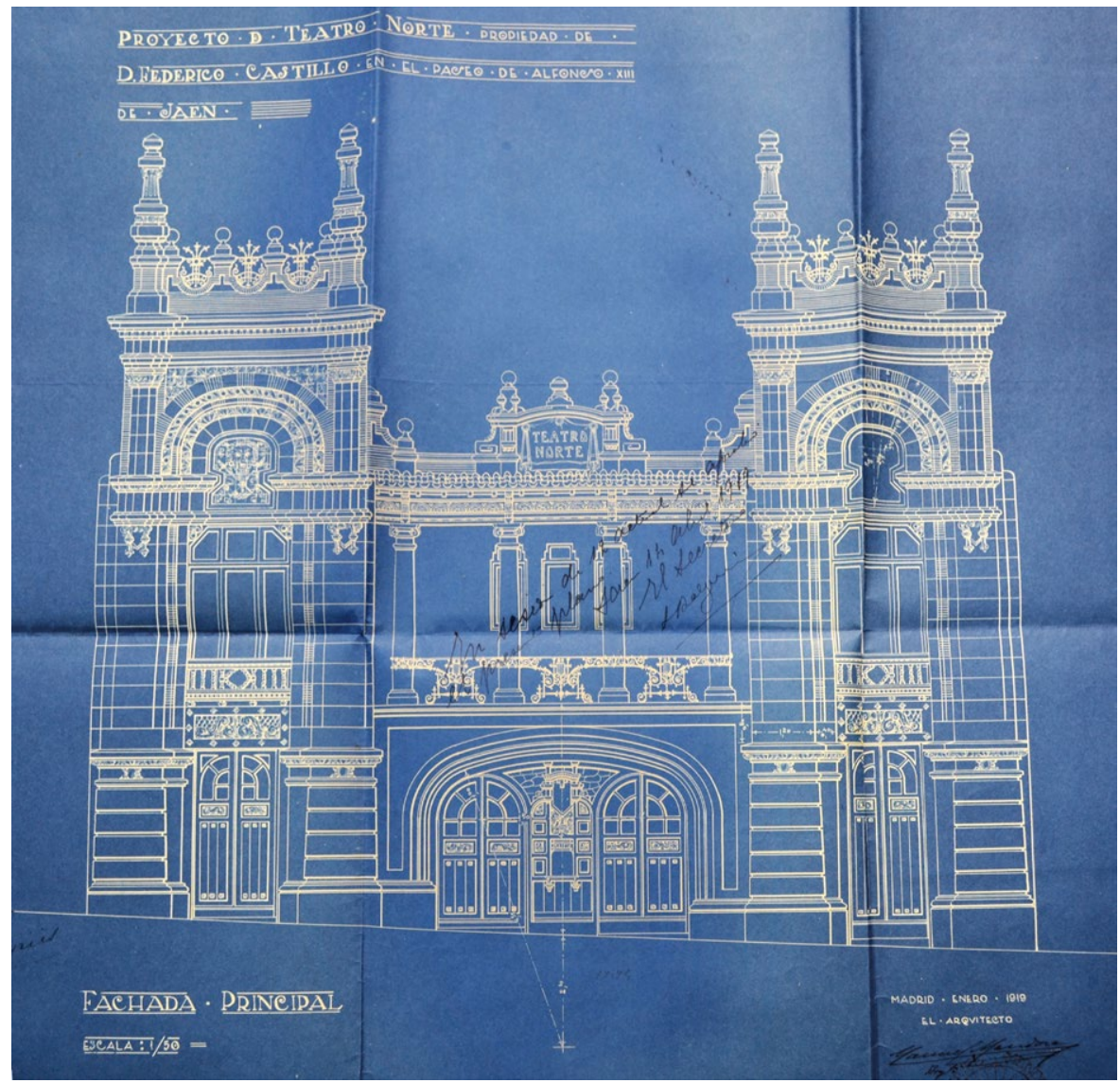

3. Cine Darymelia, Justino Flórez Llamas (1927). Foto: autor
Por ello resulta cuanto menos destacable que en los últimos años de su vida se atreviera a ensayar el estilo regionalista, tan de moda desde mediados de la década anterior, en el Darymelia $^{24}$. La fachada, no obstante, es un ejercicio bastante académico en cuanto a su composición, y que denota el arquitecto ecléctico que era Flórez. Enmarcada entre dos grandes pilastras y con una arcada triple de acceso, la cual recogía más la tradición teatral que las distintas soluciones que proponían los primeros cinematógrafos. En lo decorativo prima la sencillez, dejando casi todo el peso al contraste cromático de los propios materiales, ladrillo rojizo trabajado sin demasiada fantasía y piedra caliza. La nota regionalista se acentúa por el empleo de la cerámica, en una gran placa sobre los accesos con el nombre y año de inauguración del cine, y en otros apliques de menor tamaño en las enjutas o en la cornisa. Se trata de una obra salida del taller madrileño del ceramista Enrique Guijo ${ }^{25}$, en la que el protagonista es el elemento vegetal de tradición renacentista, con un tratamiento cercano al de la cerámica talaverana contemporánea. Otros elementos que refuerzan el carácter regionalista son el sobresaliente alero de madera y la cubierta de teja que coronan la fachada, de aspecto muy tradicional, hoy superados por un volumen añadido tras la reforma efectuada en 1992 y dirigida por Isicio Ruiz Albusac, quien modificó fundamentalmente el interior de la sala para adaptarla a teatro, función que continúa cumpliendo en la actualidad.

Ante el creciente aumento del éxito comercial del Cine en los años veinte ${ }^{26}$, Federico del Castillo, el propietario del Teatro El Norte, decide construir en 1930 una sala cubierta para la temporada de invierno en un solar contiguo del $\mathrm{Pa}-$ seo de Alfonso XIII, a la que llamó El saloncito del Norte [4]. Fue proyectada por el arquitecto municipal Antonio María Sánchez y Sánchez ${ }^{27}$ y, como ya anuncia su propio nombre, se trataba de una sala sencilla y de pequeñas dimensiones, con capacidad para no más de 350 o 400 espectadores, levantada a base de machones de mampostería y tabiquería 
de ladrillo. Al interior contaba con una planta baja en la que se encontraba el patio de butacas y una superior en la que se disponía un anfiteatro. Aunque se deben tener en cuenta tanto las limitaciones de espacio disponible, al tratarse de un solar de dimensiones reducidas, como las económicas, el proyecto de Sánchez responde en muchas cuestiones a un concepto más cercano al de las salas de cine primitivas que a las modernas que se llevaban difundiendo desde la década anterior.

Para la fachada, que seguía el mismo tono de sencillez que el resto del proyecto, el arquitecto elige una variante léxica del estilo regionalista nada habitual en la ciudad, de evocaciones hispanomusulmanas ${ }^{28}$. En Jaén es, por tanto, prácticamente nula la presencia de edificios que recreen la tradición hispanomusulmana, por ello resulta cuanto menos inusual que Sánchez utilice el arco de herradura como elemento decorativo principal a la hora de componer la fachada del Saloncito, ejecutada completamente además con ladrillo visto, aunque por otra parte sin demasiada carga decorativa adicional.

\subsection{Los cines de Jaén y la arquitectura moderna}

El comienzo de la década de 1930 es el momento de la generalización del cine sonoro en nuestro país, lo que va a obligar a los propietarios de las salas de cine a renovar los proyectores y las cabinas para adaptarlas a la nueva tecnología. En 1931 Luis Berges Martínez es el encargado de la remodelación de la cabina de proyecciones del Teatro Cervantes $^{29}$, convirtiéndose en la primera sala de la ciudad que ofrecía cine sonoro. Va a ser también con Luis Berges cuando el concepto de sala de cine moderna haga acto de aparición en Jaén, así como la aplicación a la arquitectura cinematográfica de los principios del movimiento moderno ${ }^{30}$. Sucede en 1934 con el diseño del Iris Park, en la calle de Vergara, un cine que subsistiría con diferentes nombres (Cinema España, San Carlos) hasta la década de 1980 cuando se adapta a la función de discoteca, cerrando sus puertas de forma definitiva hace unos pocos años. De nuevo estamos ante un proyecto modesto, la conversión en cine de una antigua vivienda de tamaño regular, pero en el que el arquitecto demuestra un notable conocimiento de uno de los problemas fundamentales de la tipología arquitectónica

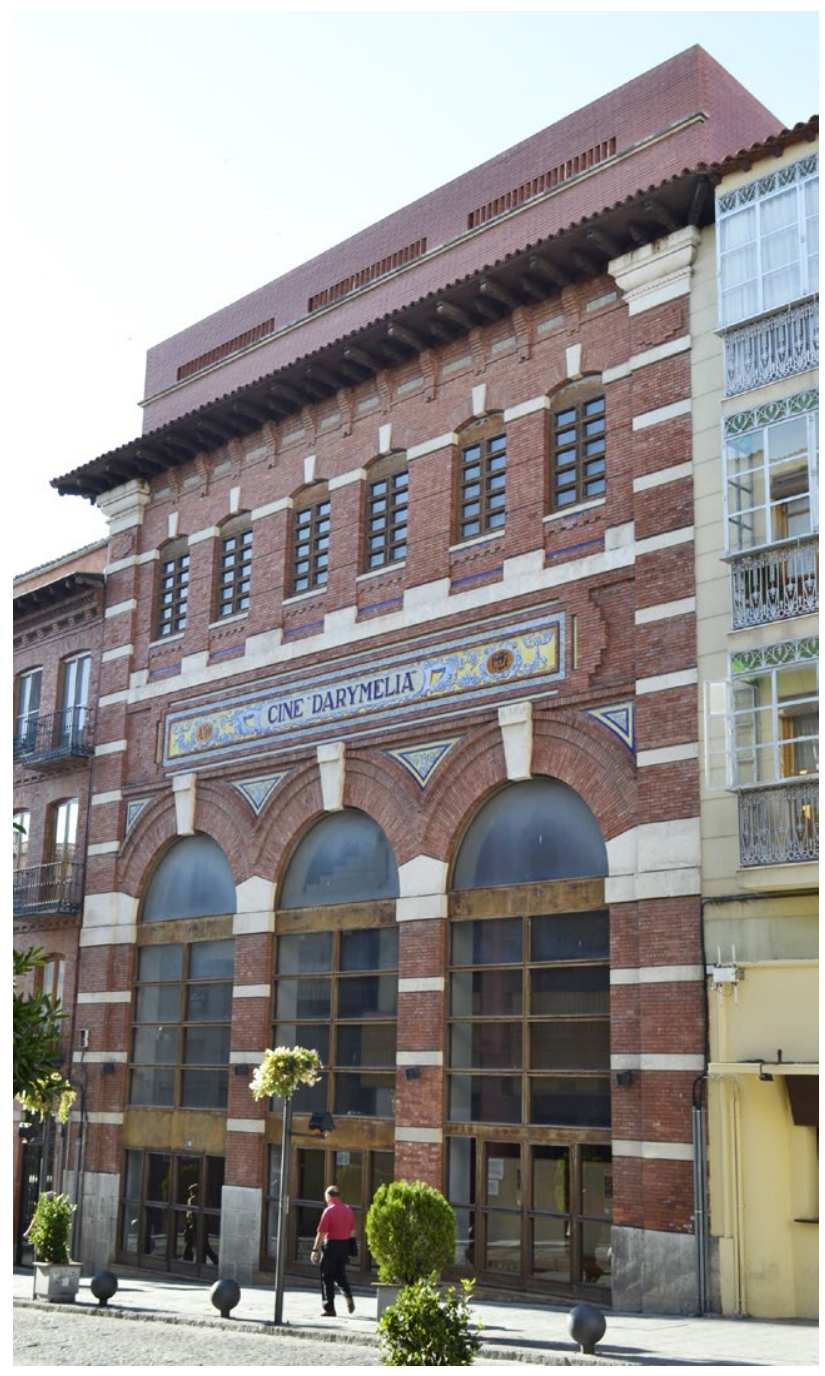

4. Fachada y planta del Saloncito del Norte, Antonio M. ${ }^{a}$ Sánchez (1930) (AMJ)

del cine, la adaptación al solar disponible para lograr una sala con la mayor rentabilidad y comodidad posibles. En la fachada apenas introdujo modificaciones, respetando casi por completo la ordenación anterior, y de paso el reducido presupuesto del propietario. Pero al interior consigue una sala de más de 600 espectadores partiendo de un solar en forma de «L», sin desaprovechar demasiado espacio y dando sensación de regularidad [5].

Por las formas utilizadas en el proyecto se percibe claramente que Berges conocía el lenguaje arquitectónico del 

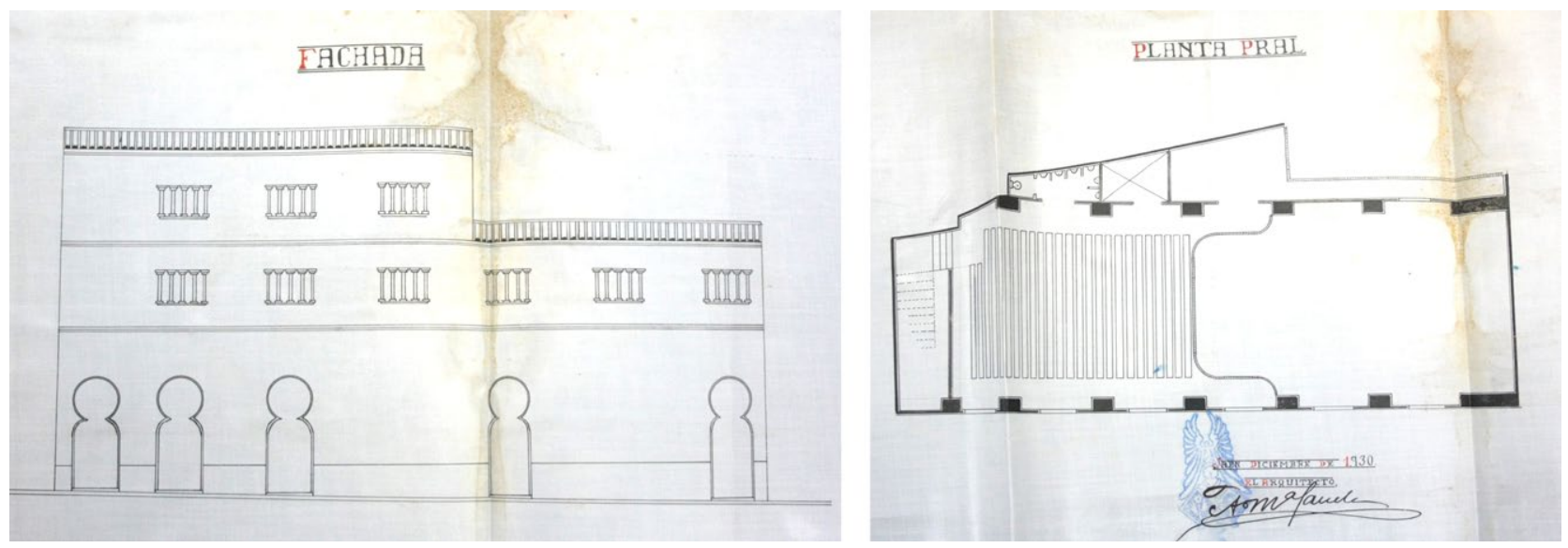

5. Cine Iris Park (planta de anfiteatro y sección), Luis Berges Martínez (1934) (AMJ)

cine moderno, que se venía formando a nivel internacional, con una aportación destacada de Alemania, desde mediados de la década de 1910. Se hace evidente, entre otras cuestiones (distribución de accesos y circulación interior, la convergencia de las paredes de la sala hacia la embocadura de la pantalla, etc.), en el diseño del anfiteatro con una línea curva habitual en las primeras salas modernas europeas. Por último, señalar de qué fuente concreta extrae Berges el conocimiento de los cines de vanguardia es entrar en el terreno de la especulación, pero merece la pena señalar que el arquitecto bien pudo conocerlos de primera mano en 1930, cuando realizó un viaje a Alemania con el objeto de documentarse para diseñar dos hospitales que le había encargado la Diputación de Jaén. Por otra parte, al igual que la gran mayoría de los arquitectos españoles de esta época, Luis Berges se encontraba suscrito a una serie de publicaciones especializadas, tanto españolas como extranjeras, además de libros de importación (Galera, 2006), en las que disponía de un importante repertorio de modelos de cines modernos a la hora de plantear el proyecto del Iris Park ${ }^{31}$.

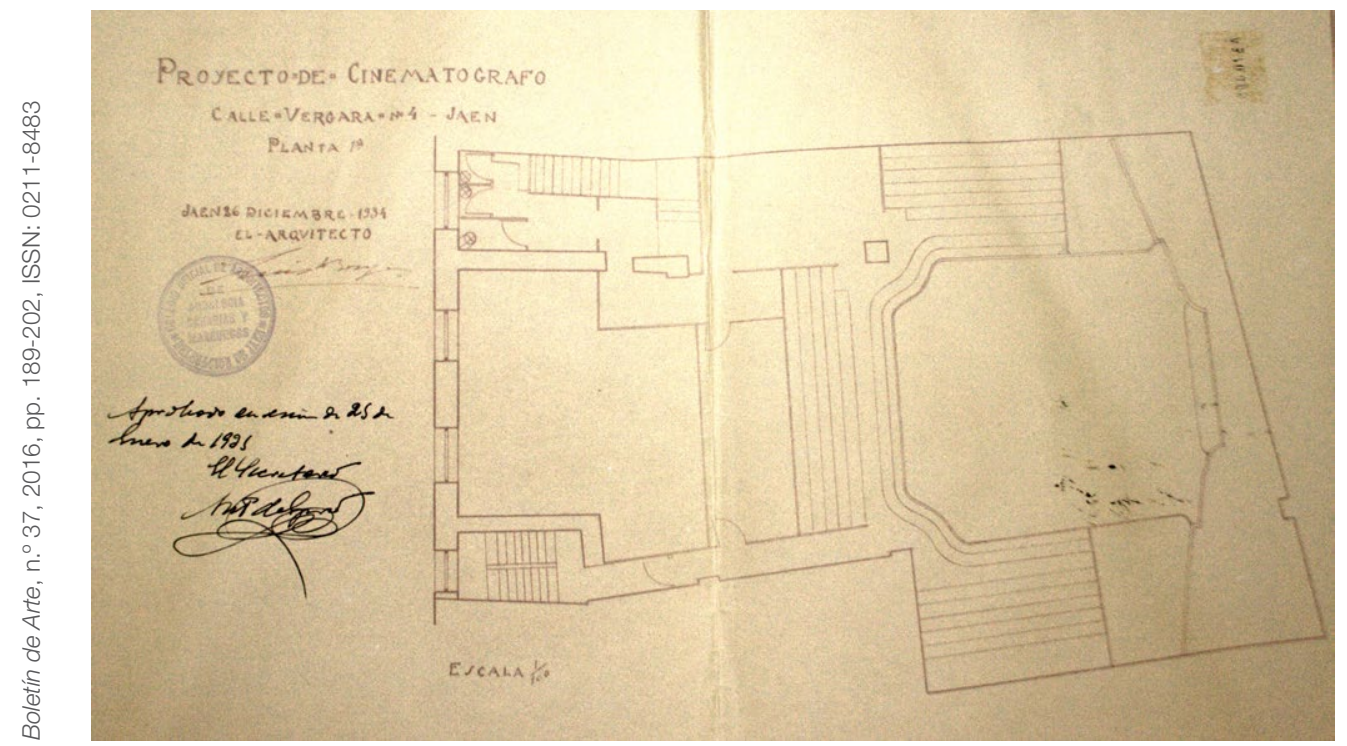

6. Primer diseño para el Cine Lis Palace (fachada y sección), Jacinto Mangas y Emilio Peña (1942) (AMJ) 
Excepción hecha del Darymelia, que pese a tener origen en un teatro, hemos visto que se debe considerar como de nueva planta, todos los cines vistos hasta el momento fueron edificios concebidos inicialmente con otra función y adaptados posteriormente para la proyección de películas, o bien pequeñas salas de condición más bien modesta. Teniendo en cuenta lo anterior, hay que considerar como uno de los primeros proyectos para construir un cine de cierta categoría en Jaén el presentado en 1942, para levantar en un solar de la calle de las Navas de Tolosa, el que acabaría convirtiéndose en el desaparecido Cine Lis Palace. Su primer proyecto, firmado por los arquitectos Jacinto Mangas y Emilio Peña ${ }^{32}$, fue diseñado ya bajo el influjo de la retórica historicista que desde el régimen franquista se intentó volcar sobre la arquitectura durante el periodo de Autarquía [6]. Preveía una sala de tamaño medio, con algo más de 1.000 localidades, y con todas las comodidades disponibles en el momento. Pero, aunque se iniciaron las obras en el mismo 1942, tras varios años de repetidos retrasos y ante la escasez de fondos librados por el propietario, el arquitecto director de las obras, Jacinto Mangas, renuncia a continuar con el proyecto y este se abandona.

Pese a que no se conserva más documentación sobre otros proyectos de obras que aporten más datos, lo que es cierto es que en diciembre de 1953 se estrena en el mismo

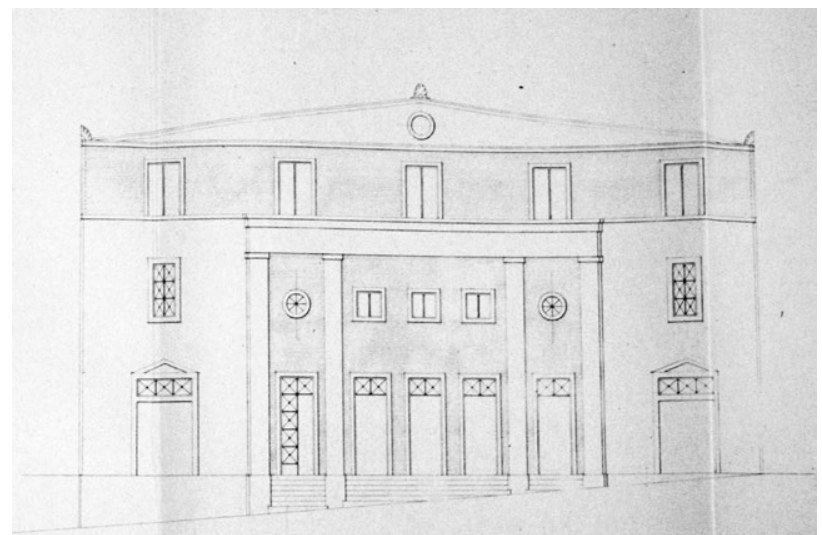

7. El Cine Lis Palace en la década de 1950 (IEG)

solar el Cine Lis Palace ${ }^{33}$, apareciendo ahora como propiedad de la empresa Norysur, que ya regentaba otros cines de la ciudad. Si bien su diseño interior respetaba en muchos aspectos el proyecto original de $1942^{34}$, para la nueva fachada se optó por una solución completamente diferente [7]. En esta fecha recién se había iniciado en España la recuperación crítica de la arquitectura del movimiento moderno tras más de una década de rechazo oficial. Si observamos la nueva fachada del Lis Palace podemos comprobar que,
8. Proyecto de reforma del Teatro El Norte (fachada), Pablo Castillo (1957) (AMJ)

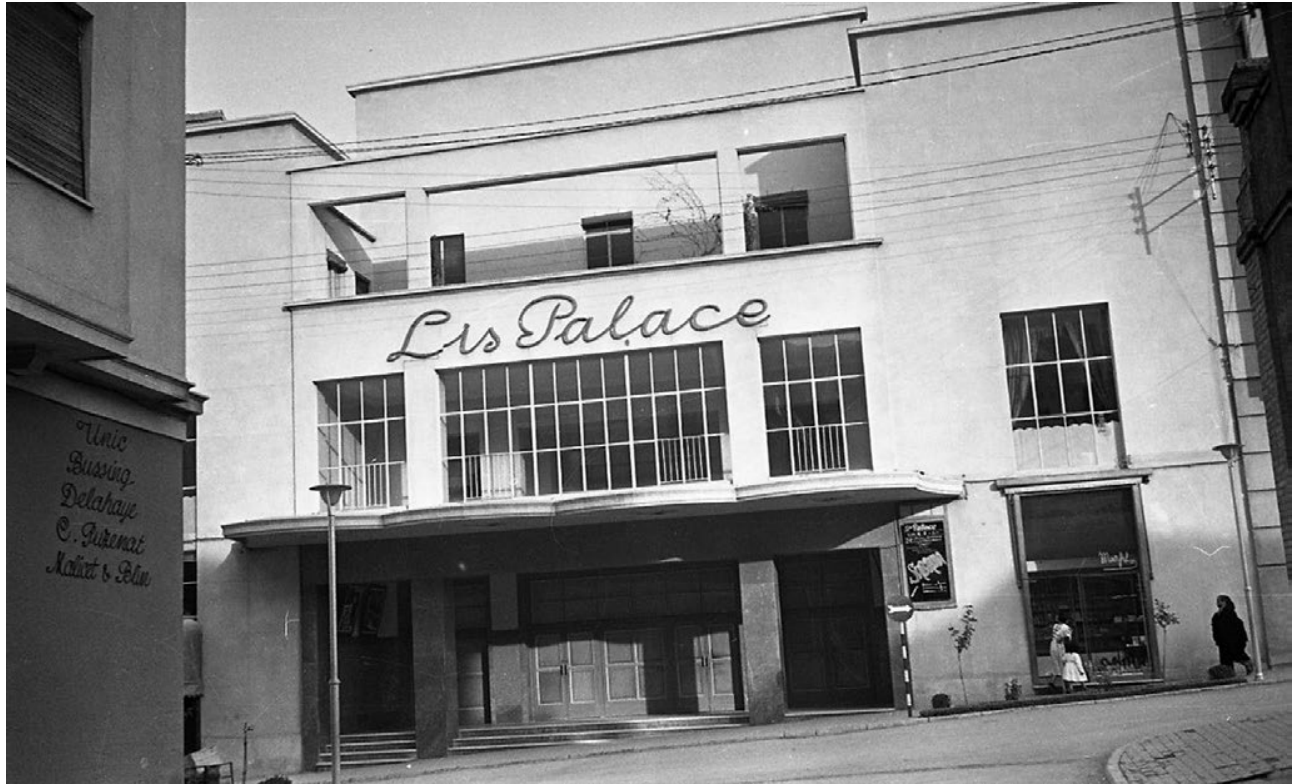




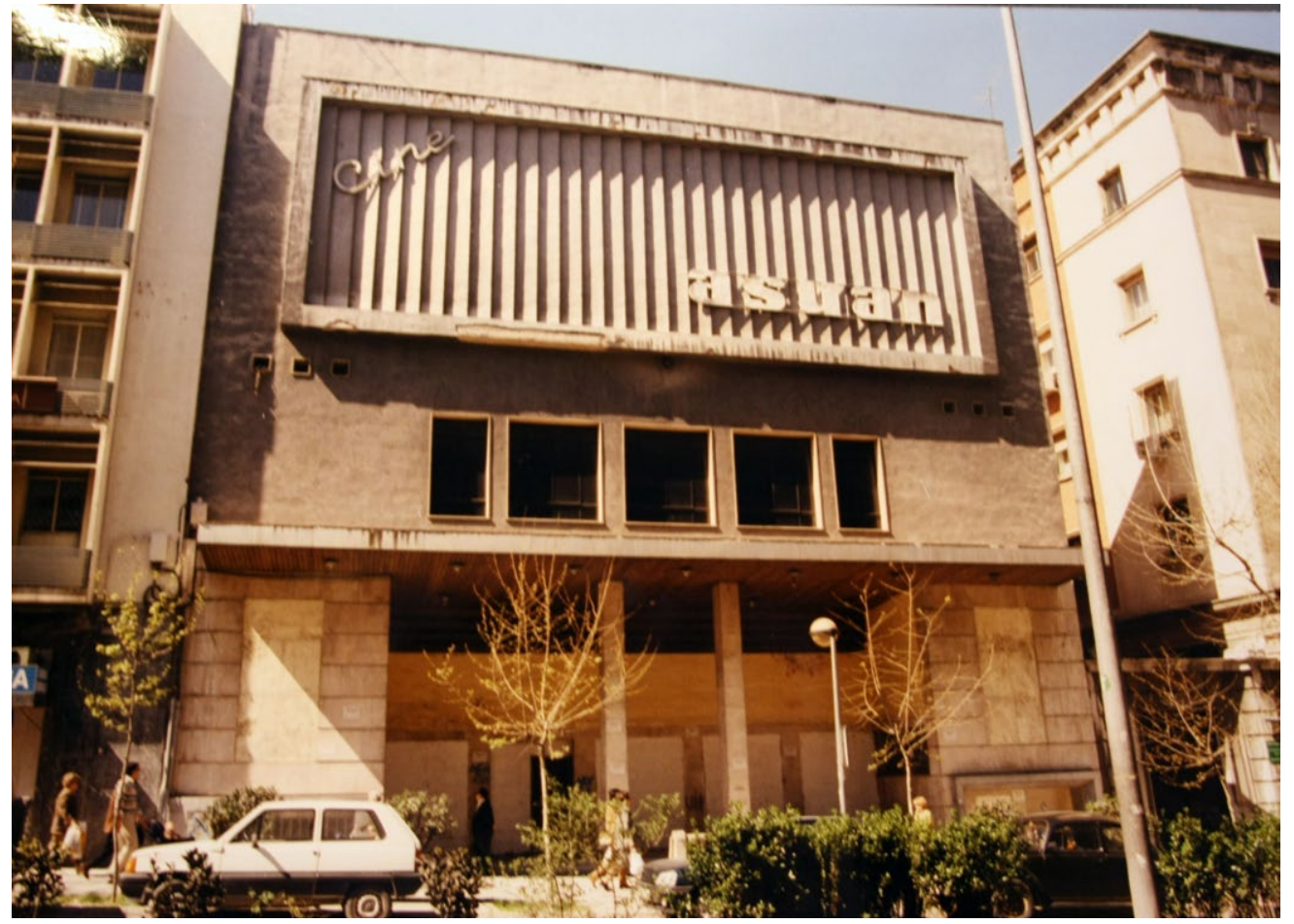

9. El Cine Asuán en los años 90, poco después de su cierre (IEG) pese a trazarse con unas líneas y un léxico completamente modernos, introduciendo elementos como una pérgola de cemento sobre la terraza-ambigú, el amplio ventanal central o la marquesina de cemento de líneas onduladas sobre los accesos, mantiene en esencia el mismo esquema compositivo que el diseño de Mangas y Peña en 1942. Conserva la idea del pórtico central con dos pilares, las mismas alturas y parecidos volúmenes, e incluso casi exacta disposición de vanos, lo que puede inducir a pensar que cuando se produjo el cambio en la dirección de la obra, probablemente, esta se encontraba ya muy avanzada. Del autor del nuevo proyecto de fachada no queda testimonio documental, aunque se pueden encontrar razones suficientes para acercar el diseño a la obra de Pablo del Castillo, arquitecto giennense que en estos años iniciales de la década de 1950 es el único de la capital del que se registran edificios de una estética moderna tan rotunda como esta fachada ${ }^{35}$. Entre los motivos que podrían justificar la autoría de Pablo del Castillo para el Lis Palace lo encontramos en el proyecto ${ }^{36}$ que en 1957 firma para la remodelación del antiguo Teatro el Norte y su conversión en sala de cine cubierta. Diseña una fachada en la que vuelven a aparecer algunos elementos vistos en la del Lis Palace [8], como por ejemplo, el pórtico de acceso con dos pilares, la azotea con pérgola de cemento o los grandes vanos tanto en el plano central como en los laterales.

Un proyecto este que no se materializaría, pero que sería el germen del Cine Asuán (1966) [9], obra igualmente de Castillo (W. AA., 1990: 226-229). Propiedad también de la empresa Norysur, dirigida por Juan Ramírez de Torres, uno de los personajes centrales del negocio cinematográfico en la ciudad, va a ser el último cine que se va a construir en el siglo XX en Jaén, entendido como edificio dedicado por entero a esta función, siendo demolido en el año 2001 tras casi diez de cierre. Pese a que no se ha podido localizar su proyecto de obras, sí conocemos su estructura y concepción espacial$^{37}$. El edificio del Cine Asuán se dividía en un módulo inicial con recibidor y accesos a la sala, que contaba con platea en planta baja y un anfiteatro volado en la superior, con capacidad entre ambas para unos 1100 espectadores, y una caja de escenario con la pantalla y otras dependencias al fondo, ya que se pretendía que el cine albergara otros tipos de espectáculos (conciertos, galas, etc.). Su fachada, en la que se 
refleja ya la estética del Estilo Internacional tardío, con cierto gusto manierista incluso, se componía de un cuerpo inferior, una vez más en un cine de Pablo del Castillo con un pórtico con dos pilares centrales y cinco puertas de acceso, y uno superior formado por un gran plano en el que se abre un juego de vanos de distintos tamaños correspondientes al hall de la entreplanta y a los aseos, todo con un tratamiento muy geométrico. Sobre ellos una moldura rectangular de grandes dimensiones en la que el arquitecto dispuso una serie de líneas verticales en forma de acordeón, de gran dinamismo, colocando dentro de ella el nombre del cine, avisando con este recurso de la función del mismo, al crear la ilusión de trasladar la pantalla del interior de la sala a la avenida, actuando a modo de reclamo para el paseante.

\section{Conclusiones}

Los espacios que el cine ocupa a lo largo de su desarrollo en la ciudad, se pueden interpretar como un reflejo directo de la consideración que merece para el público de cada momento. No solamente en cuanto a la entidad del propio edificio, sino también en lo relativo al prestigio de las zonas urbanas en las que se establecen. Se puede encontrar una relación directa entre la popularidad, e incluso la progresiva consideración del cine como medio cultural de masas, y la categoría de las arquitecturas que lo acogen. De los barracones cinematográficos de la primera década del siglo en los que se instala cuando aún no es sino una novedad, una atracción de feria más, a las «máquinas» tecnológicas en que acaban convirtiéndose en su momento de máximo esplendor a partir de la década de 1950, el edificio destinado a la proyección cinematográfica deja ver qué significa el cine para la sociedad que lo construye. Aunque es un aspecto en el que no hemos ahondado en este trabajo, igual situación se puede observar en relación a los espacios urbanos en los que se establecen los cines en Jaén a lo largo del siglo.

Por otra parte, en Jaén, como en muchas pequeñas ciudades de provincia y en especial en una Andalucía rendida casi por completo al regionalismo arquitectónico, con recursos económicos muy limitados y con una población en líneas generales no tan sensible a la estética moderna, la introducción de los estilos arquitectónicos de vanguardia durante los años 20 y 30, momento crucial en la gestación de la tipología del cine, es lenta, escasa en ejemplos y cuando se encuentra es normalmente una adopción epidérmica del estilo. Es por ello que en la capital giennense, exceptuando el modesto ejemplo del Iris Park de Luis Berges, no contamos con cines déco o racionalistas, habituales en ciudades de mayor tamaño, mientras que los pocos proyectos que se ejecutan en estos años, como por ejemplo la intervención en el Darymelia o El Saloncito del Norte, dejan ver el peso del regionalismo arquitectónico. Otro caso distinto ocurre con la recuperación de la arquitectura moderna a partir de los años 50 del siglo pasado. La obra de arquitectos como Pablo Castillo se mantiene como muestra de la vigencia de la tipología arquitectónica de la sala de cine durante la etapa de recuperación de la arquitectura moderna en España, dando lugar a destacados ejemplos, como los vistos del Lis Palace o el Asuán.

Precisamente con esta última sala se cierra la etapa dorada del cine en Jaén. Desde los últimos años sesenta del siglo pasado, el cine como espectáculo de masas va a entrar paulatinamente en recesión, en parte por el efecto de otros medios de entretenimiento de masas como la televisión, llegando a una crisis que provocó una epidemia masiva de cierre de salas por todo el país, en la cual aún hoy parece encontrarse, y que repercutido en la desaparición, o mala conservación por abandono, de buena parte de los cines. De los distintos edificios tratados en este trabajo solamente se mantienen en pie dos, el Darymelia ${ }^{38}$ y el antiguo Iris Park (enormemente transformado y en desuso desde hace años), pese a la gran valía arquitectónica y cultural presente en buena parte de los mismos. Aunque en los últimos años han sido varias las iniciativas públicas destinadas a contribuir a la recuperación y protección de salas de cines históricas de España, desde el Programa de Rehabilitación de Teatros de Andalucía de la Junta de Andalucía a lo largo de la década de 1990, o la realización de un inventario de salas cinematográficas para el Plan Nacional de Patrimonio del siglo XX (2014), la singular vulnerabilidad de la tipología arquitectónica del cine la hacen merecedora de un especial esfuerzo protector por parte del resto de agentes sociales. 


\section{Notas}

1 Albacete y Guadalajara (1897), Cartagena, Murcia y Badajoz (1898), Cádiz (1901), Sevilla y Almería (1902) o Jerez (1903) entre otras. Además de la citada obra de Mónica Barrientos se recogen noticias de la actividad de Antonio de la Rosa en Garófano (1997), Cerón (1997) y Ruiz Rojo (1997).

2 Eco Artístico, 5 de diciembre de 1910: p. 11.

3 Pueblo Católico, 9 de mayo de 1898.

4 Comprendía las actuales plazas de la Constitución y del Deán Mazas, que fueron separadas a principios de la década de 1930 tras la construcción del edificio para la delegación de Hacienda.

5 Son varias las obras literarias de distintas épocas que hacen mención expresa a esta condición. Por ejemplo, desde Hechos del Condestable don Miguel Lucas de Iranzo (anónimo del último tercio del siglo XV), hasta Retrato natural de la ciudad y término de Jaén (1794) de José Martínez Mazas se relata la celebración de corridas de toros y otras fiestas, normalmente de carácter profano, en la plaza del Mercado.

6 Archivo Municipal de Jaén (AMJ), leg.1063 (25), 1903.

7 A este respecto véase el ya citado trabajo de Jesús Ángel Sánchez (2013).

8 Un caso destacable es el del cinematógrafo que diseña el arquitecto Francisco de Paula Casado en 1908 para la calle Argüelles de Linares, y que, pese a ser convertido en supermercado en fechas recientes, su llamativa fachada ecléctica aún se conserva en buen estado. Sobre esta sala véase Casuso (2008: 396).

9 Pueblo Católico, 22 de enero de 1906.

10 Pueblo Católico, 9 de febrero de 1906.

11 En Jaén esto ocurre en febrero de aquel mismo año de 1906, tras haber pasado el mes anterior en el Apolo, el cinematógrafo que se encontraba en la ciudad se anuncia en el Salón Iris, partiendo hacia Andújar unos días después (Pueblo Católico, 19 de febrero de 1906).

12 Con un presupuesto de 135.000 pesetas, resuelto en 1905 en los salones del Círculo Mercantil en la Carrera (La Época, 13 de octubre de 1905: 3).

13 AMJ, Proyecto del Teatro Cervantes, 2299003, 1905.

14 Pueblo Católico, 8 de enero de 1909.

15 Pueblo Católico, 21 de julio de 1910.

16 Por ejemplo la actual sede del PSOE en la calle de Hurtado (ca. 1905) (Padilla; Casuso y Ortega, 2008: 164), así como una desaparecida vivienda en la de Bernabé Soriano (ca. 1910) (Rueda, 2015: 69 y 70), compartían con la primitiva fachada de El Norte elementos casi idénticos en sus fachadas, en concreto un friso con decoración vegetal realizada en yeso, característica de la estética Art Nouveau.

17 Pueblo Católico, 20 de junio de 1912.

18 AMJ, Expediente relativo a la solicitud de D. Federico Castillo para la modificación de fachada del Teatro El Norte, en el Paseo de Alfonso XIII, leg.1668 (23), 1919.

19 Un recurso, por cierto, procedente de las tipologías de edificios para espectáculos y que los primeros cines recogían por su potencial para el reclamo (Sánchez, 2013: 264-265).

20 Pueblo Católico, 30 de enero de 1903.

21 En 1906, poco antes del estreno del Cervantes, Flórez cierra el teatro y lo adapta a almacenes (Casuso, 1998: 129-130).

22 AMJ, Proyecto de reforma del Teatro Principal de la Plaza de la Audiencia, 3556001, 1923.

23 Influido además por el racionalismo de Viollet-le-Duc, no en vano había sido discípulo de uno de los más importantes arquitectos de esta tendencia del XIX español, Juan de Madrazo y Kuntz, a quien se mantuvo cercano durante sus años de estudio en la Escuela de Arquitectura de Madrid (Lázaro, 1901:18).

24 No fue la primera vez en la que Justino Flórez utilizó el lenguaje regionalista, en 1919 ya había coqueteado con este estilo en la reforma del cercano Casino Primitivo, aunque en esencia se debe considerar un edificio más en la línea del eclecticismo decimonónico.

25 Enrique Guijo (1871-1955), pintor, decorador y ceramista de origen cordobés, aunque formado en Triana, responsable junto a Juan Ruiz de Luna del resurgir de la cerámica de Talavera en la primera década del siglo XX. Sobre la figura de Guijo véanse los trabajos de Sánchez-Cabezudo (2005 y 2010$)$; o el mucho más antiguo de Cascales Muñoz (1929), que ofrece probablemente algunos de los primeros datos sobre el artista.

26 No estamos atendiendo a los cines de verano en este trabajo, los cuales pese a su mayor sencillez constructiva acaparaban buena parte de la afluencia de público, y que tuvieron en la ciudad una época de esplendor durante el periodo 1940-1960, con más de diez aperturas. Ya en la década de 1920 se registran al menos dos: el Trianon, abierto al público hacia 1925 en el paseo de Alfonso XIII, y otro que instaló la empresa del Teatro Cervantes en el solar dejado por la demolición de las antiguas Carnicerías en la plaza de San Francisco en 1928, funcionando de forma discontinua hasta el comienzo de las obras del edificio de Correos en el mismo en 1933 (AMJ, Licencia de apertura de un cinematógrafo, leg. 1609 [22], 1928).

27 AMJ, Expediente para la construcción de un cinematógrafo en el Paseo del Alfonso XIII, leg. 884(27), 1930.

28 El regionalismo de los años 20 en la capital giennense, protagonizado principalmente por la obra de los arquitectos Luis Berges Martínez, Antonio Flórez Urdapilleta y Emilio Moreno Callejón, es fundamentalmente de tendencia clasicista, más bien austero en lo decorativo y de cierto ascendente castellano, y elige el renacentista como lenguaje de referencia a recuperar, del cual la provincia cuenta con una especial riqueza de ejemplos en los que inspirarse. Además, de forma general, desde principios de siglo existió en la ciudad una mayor identificación a nivel cultural con el legado arquitectónico de los siglos XVI al XVIII que, por ejemplo, con el medieval, que sí fue referencial en el regionalismo de otras capitales andaluzas por la existencia de grandes monumentos de este periodo. No sucede otro tanto en poblaciones del oeste de la provincia, como Andújar o Martos, más expuestas a la influencia de los focos sevillano y cordobés.

29 AMJ, Proyecto de cabina para cinematógrafo sonoro en el Teatro Cervantes, leg. 1734 (24), 1931.

30 Si bien el único cine construido en la ciudad de Jaén con anterioridad a la Guerra Civil, diseñado según los preceptos del movimiento moderno es este de Luis Berges, del cual nos ocupamos a continuación, no hay que olvidar la presencia en la provincia de algún interesante ejemplar de nuestra vanguardia de los años 30. Es el caso del Cine Tívoli de Andújar, obra de José Corbella y Francisco Alzado (1933-34), al que, además de representar uno de los primeros 
ejemplos andaluces de introducción en la tipología del cine de las formas derivadas de las vanguardias centroeuropeas, le cabe el honor de ser uno de los primeros edificios de la provincia de Jaén construidos con estructura de hormigón armado (García Vázquez y Pico Valimaña, 1999: 52-55).

31 Entre estos últimos el arquitecto poseía una obra del arquitecto alemán y editor de la revista Berliner Architekturwelt, Hans Schliepmann, titulada Lichtspieltheater, eine Sammlung ausgeführter Kinohäuser in Gro $\beta$-Berlin (1914), un clásico de la literatura sobre las primeras salas de cine que, como indica su título, recogía una colección de los ejemplos construidos en Berlín hasta la fecha de su edición. No obstante la arquitectura que aparece en el libro de Schliepmann se antoja en principio algo anticuada si atendemos a las formas utilizadas por Berges. Resulta más verosímil que se sirviera en todo caso de los múltiples ejemplos que, sin ir más lejos, le ofrecía la revista de la Sociedad Central de Arquitectos, Arquitectura, que entre 1926 y la fecha del proyecto del Iris Park publicó una importante serie artículos sobre cines en los que se recogía un catálogo amplio de soluciones modernas. En concreto aparecieron en sus páginas noticias con material gráfico sobre el Capitol de Berlín, de Poelzig (1926, n. 89); el Palacio de la Música de Madrid, de Zuazo (1926, n. 92); el Callao de Madrid, de Gutiérrez Soto (1927, n. ${ }^{\circ}$ 94); el Universum de Berlín, de Mendelsohn (1929, n. ${ }^{\circ}$ 118); el San Carlos de Madrid, de Eduardo Lozano (1929, n. ${ }^{123)}$; el Fígaro de Felipe López Delgado y el Tetuán de Riancho y De la Torriente, ambos en Madrid (1932, n. ${ }^{154)}$ (el interior de este último es el que más similitudes presenta con el del Iris) y el Actualidades de Madrid, de Saturnino Ulargui $\left(1933\right.$, n. $\left.^{\circ} 169\right)$.

32 AMJ, 1056003, 1942

33 Diario Ideal, 12 de diciembre de 1953

$34 \mathrm{Si}$ atendemos a las fotografías de época que se conservan del interior de la sala. Algunas de ellas disponibles en la colección fotográfica del Instituto de Estudios Giennenses.

35 Aunque su obra es aún relativamente desconocida, Pablo Castillo es uno de los arquitectos pioneros en la introducción de la arquitectura moderna en la capital giennense desde principios de la década de 1950, y sin duda uno de los que mejores resultados obtuvo de su empleo. Ejemplos destacables dentro de su obra, además de los cines aquí tratados, son el edificio de oficinas proyectado en el actual n. ${ }^{\circ} 11$ del Paseo de la Estación (1961) (del cual solamente se conserva una parte de su extensión original), o el proyecto, en colaboración con Manuel Millán, del edificio para los grandes almacenes Tejidos Gangas (1958) (hoy sede del Servicio Andaluz de Empleo en la plaza de San Francisco). Acerca de ambos véase Padilla; Casuso y Ortega (2008).

36 AMJ, 1072001, 1957

37 Para documentar el edificio del Cine Asuán, además de la obra ya citada, Arquitectura teatral y cinematográfica: Andalucía 1800-1990, cuyos autores sí tuvieron acceso al proyecto de obras, contamos con un proyecto de instalación eléctrica del mismo año de su construcción (AMJ, 502015, 1966), el cual incluye la documentación gráfica que aquí se ofrece.

38 Convertido en teatro en los años 90 gracias a que fue seleccionado por el Programa de Rehabilitación de Teatros de Andalucía llevado a cabo por la Consejería de Obras Públicas y Transporte de la Junta de Andalucía.

\section{Bibliografía}

BARRIENTOS BUENO, Mónica (2003), Antonio de la Rosa, empresario pionero del cinematógrafo en Sevilla (1902-1907). Cuadernos de EIHCEROA n. ${ }^{\circ}$ 3, Padilla Libros, Sevilla.

CÁNOVAS BELCHI, Joaquín (1993), «Las primeras sesiones del cinematógrafo Lumière en Madrid», Imafronte, N. ${ }^{\circ} 8-9$ (Ejemplar dedicado a: Homenaje a la profesora Virginia de Mergelina), pp. 105-112

CASCALES MUÑOZ, José (1929). Las bellas artes plásticas en Sevilla. La pintura, la escultura, y la cerámica artística desde el siglo XIII hasta nuestros días. Apuntes históricos y biográficos, Tomo II, Colegio de Huérfanos de María Cristina, Toledo.

CASUSO QUESADA, Rafael (1998), Arquitectura del siglo XIX en Jaén, Instituto de Estudios Giennenses, Jaén.

- (2008), "Arquitectura ecléctica en Linares en el primer tercio del siglo XX», en LEIS SÁNCHEZ, Vicente; MARTíNEZ AGUILAR, Lorenzo; RABANEDA SÁNCHEZ, Luis (coords.), Actas I Congreso de Historia de Linares, Centro de Estudios Linarenses-Diputación Provincial de Jaén, pp. 393-406.

CERÓN GÓMEZ, Juan Carlos (1997), «El cinematógrafo en Murcia (1896-1914)», en MADRID, Juan Carlos de la (coord.), Primeros tiempos del cinematógrafo en España, TREA, Gijón, pp. 175-193

CORONAS TEJADA, Luis (1983), «La Casa de Comedias y noticias de teatro en el Jaén del siglo XVIl», en GARCíA LORENZO, Luciano (ed.), Calderón. Actas del Congreso Internacional sobre Calderón y el teatro español del Siglo de Oro, Tomo III, CSIC, Madrid, pp. 1545-1558.

GALERA ANDREU, Pedro (2006). «Modernidad y tradición», en BERGES ROLDÁN, LUIS, Arquitecto Berges (1891-1939), Tinta Blanca, Jaén, pp. 110-117

LARA GARCÍA, María Pepa (1999), Historia del cine en Málaga, Editorial Sarriá, Málaga.

GARCÍA VÁZQUEZ, Carlos; PICO VALIMAÑA, Ramón (dirs.) (1999), MoMo Andalucía. Arquitectura del Movimiento Moderno en Andalucía 1925-1965, Consejería de Obras Públicas y Transportes-Junta de Andalucía, Sevilla. 
GARÓFANO, Rafael (1997), «De llegada de un tren a la estación a Cabiria, en Cádiz», en MADRID, Juan Carlos de la (coord.), Primeros tiempos del cinematógrafo en España, TREA, Gijón, pp. 149-172.

HURLEY, Isabel (1996), «Culminación del proyecto de ciudad burguesa en Jaén: el Teatro Cervantes de Manuel Rivera Vera», Boletín de Arte, n. ${ }^{\circ} 17$, pp. 349-366.

ISAC MARTÍNEZ DE CARVAJAL, Ángel (2010), Crecimiento urbano y arquitectura contemporánea en Granada 1951-2009, Universidad de Granada, Granada.

LÁZARO DE DIEGO, Juan Bautista (1901), «Catedral de León», La Lectura, n. 5, pp. 9-23.

MARTÍNEZ MAZAS, José (1794), Retrato al natural de la ciudad y término de Jaén, Imprenta de Pedro de Doblas, Jaén.

MATA CARRIAZO, Juan de (1940) (Ed.), Hechos del Condestable don Miguel Lucas de Iranzo (Crónica del siglo XV), Espasa-Calpe, Madrid.

PADILLA SÁNCHEZ, José Gabriel; CASUSO QUESADA, Rafael Antonio; ORTEGA MONTORO, Amelia (2008), Jaén. Guía de Arquitectura, Colegio Oficial de Arquitectos de Jaén, Consejería de Vivienda y Ordenación del Territorio, Junta de Andalucía, Jaén y Sevilla.

PÉREZ ROJAS, Francisco Javier (1986), «Los cines madrileños: del barracón al rascacielos», en W. AA., El cinematógrafo en Madrid 18961960, Vol. II, Ayuntamiento de Madrid, Madrid.

ROCHA ARANDA, Óscar da (2009), El modernismo en la arquitectura madrileña. Génesis y desarrollo de una opción ecléctica, Consejo Superior de Investigaciones Científicas, Madrid.

RUEDA GALÁN, Luis (2015), La Carrera de Jaén. Historia, urbanismo y arquitectura (Trabajo fin de máster inédito). Departamento de Patrimonio Histórico, Universidad de Jaén, Jaén.

RUIZ ROJO, José Antonio (1997), «La exhibición cinematográfica en Guadalajara (1897-1914): un ensayo de cronología», en MADRID, Juan Carlos de la (coord.), Primeros tiempos del cinematógrafo en España, Trea, Gijón, pp. 281-300.

SÁNCHEZ GARCÍA, Jesús Ángel (2013), «Un desfile de máscaras. Pabellones cinematográficos y difusión del Art Nouveau en las ciudades españolas (1900-1914)», en BOSCH, Lluís y FREIXA, Mireia (coord.), Actas del CDf International Congress, Universidad de Barcelona, Barcelona, pp. 264-275.

SÁNCHEZ-CABEZUDO GÓMEZ, Ángel (2005), «Enrique Guijo, un ceramista esencial en el siglo XX», en La cerámica española y Don Quijote, Empresa Pública Don Quijote de La Mancha, Toledo, pp. 331-340.

- (2010), «Enrique Guijo, artista esencial en el historicismo cerámico de Talavera», en GONZÁLEZ MORENO, Fernando (ed.), Renacimientos: la cerámica española en tiempos de Ruiz de Luna, Universidad de Castilla la Mancha, Cuenca, pp. 25-36.

ULIERTE VÁZQUEZ, Luz de (1990), Jaén, la ciudad y su historia, Centro de Estudios Provinciales y de Cooperación Interprovincial, Granada.

W. AA. (1990), Arquitectura teatral y cinematográfica: Andalucía 1800-1990, Dirección General de Fomento y Promoción Cultural, Junta de Andalucía, Sevilla. 